\title{
Review Article \\ Surgical Management of Endometrial Polyps in Infertile Women: A Comprehensive Review
}

\author{
Nigel Pereira, ${ }^{1}$ Allison C. Petrini, ${ }^{2}$ Jovana P. Lekovich, ${ }^{1}$ \\ Rony T. Elias, ${ }^{1}$ and Steven D. Spandorfer ${ }^{1}$ \\ ${ }^{1}$ The Ronald O. Perelman and Claudia Cohen Center for Reproductive Medicine, Weill Cornell Medical College, \\ 1305 York Avenue, 6th Floor, New York, NY 10021, USA \\ ${ }^{2}$ Department of Obstetrics and Gynecology, Weill Cornell Medical College, 1305 York Avenue, 6th Floor, New York, NY 10021, USA \\ Correspondence should be addressed to Steven D. Spandorfer; sdspando@med.cornell.edu
}

Received 18 June 2015; Accepted 26 July 2015

Academic Editor: Giampiero Capobianco

Copyright (C) 2015 Nigel Pereira et al. This is an open access article distributed under the Creative Commons Attribution License, which permits unrestricted use, distribution, and reproduction in any medium, provided the original work is properly cited.

Endometrial polyps are benign localized lesions of the endometrium, which are commonly seen in women of reproductive age. Observational studies have suggested a detrimental effect of endometrial polyps on fertility. The natural course of endometrial polyps remains unclear. Expectant management of small and asymptomatic polyps is reasonable in many cases. However, surgical resection of endometrial polyps is recommended in infertile patients prior to treatment in order to increase natural conception or assisted reproductive pregnancy rates. There is mixed evidence regarding the resection of newly diagnosed endometrial polyps during ovarian stimulation to improve the outcomes of fresh in vitro fertilization cycles. Hysteroscopy polypectomy remains the gold standard for surgical treatment. Evidence regarding the cost and efficacy of different methods for hysteroscopic resection of endometrial polyps in the office and outpatient surgical settings has begun to emerge.

\section{Introduction}

The interaction between an embryo and a receptive endometrium forms a critical part of early implantation subsequently allowing for placentation and continuation of a healthy pregnancy $[1,2]$. It is believed that intrauterine abnormalities, such as polyps, leiomyomata, or synechiae, may perturb this important event $[2,3]$. Although isolated uterine-associated infertility can be found in $2-3 \%$ of infertile women [4], intrauterine lesions may be found in approximately $40-50 \%$ of subfertile or infertile women [4-6]. Lesions such as endometrial polyps have previously been implicated in the pathogenesis of subfertility and early pregnancy loss, though this association is sometimes debated $[5,6]$. Previous observational studies have suggested that resection of endometrial polyps can help increase natural conception rates as well as increase pregnancy rates with assisted reproduction [4]. In this paper, we review the epidemiology, pathogenesis, diagnosis and management of endometrial polyps in infertile women. We also critically evaluate the current evidence related to resection of endometrial polyps and its impact on natural conception and assisted reproductive pregnancy rates.

\section{Epidemiology}

Endometrial polyps are benign localized outgrowths of the endometrium that contain glands and stroma $[5,7]$. They may occur as single or multiple lesions, can be sessile or pedunculated, and may range in size from millimeters to centimeters $[2,7]$. Occasionally, endometrial polyps may contain smooth muscle fibers in addition to glands and stroma and are called adenomyomatous polyps [8]. The true incidence of endometrial polyps remains unknown incidence due to its asymptomatic nature [9]. However, depending on the type of population studied, the prevalence of endometrial polyps can vary from $7.8 \%$ to $34.9 \%[10,11]$. Some studies have reported that endometrial polyps can be found in up to $24 \%$ of symptomatic women $[12,13]$. The prevalence of 
endometrial polyps is thought to be higher in infertile women [9]. In a prospective study of 1000 patients undergoing hysteroscopic evaluation of the uterine cavity prior to in vitro fertilization (IVF), the prevalence of endometrial polyps was found to be $32 \%$ [14]. While this may suggest a causal association between polyps and infertility, this association has been confirmed in only one randomized control trial so far [15].

\section{Pathogenesis}

Endometrial polyps are rarely diagnosed before menarche [16] suggesting that estrogenic stimulation of the endometrium plays a crucial role in the pathogenesis of endometrial polyps [17]. As these polyps contain immature or functional endometrium, they can develop in conditions associated with increased or unopposed estradiol levels, as in the case of ovarian stimulation during IVF [18]. Age, hypertension, obesity, and diabetes are well known risk factors for the development of endometrial polyps $[19,20]$. Of these risk factors, age is perhaps the most well-known risk factor [9]. The prevalence of endometrial polyps increases with age, though it is unclear whether this trend continues past menopause [9]. There also appears to be an association between endometrial polyps and other benign gynecologic conditions such as cervical polyps and endometriosis [21,22]. Women using tamoxifen are also known to have a higher risk of developing endometrial polyps, and the prevalence of polyps in this patient population is estimated to be between 30 and $60 \%$ [23]. Molecular mechanisms such as the overexpression of estrogen and progesterone receptors [24], endometrial aromatase $[25,26]$, increased B-cell lymphoma 2 protein expression [27], and mutations in the HMGIC and $H M G I[Y]$ genes $[28,29]$ have also been implicated in the development of endometrial polyps. Atypical hyperplasia and endometrial cancer may arise in up to $6.7 \%$ and $2.2 \%$ of endometrial polyps, respectively [30-33]. The risk of malignancy increases with age [9], polyp size [34], and concomitant use of tamoxifen [35].

\section{Diagnosis}

Patients with symptomatic endometrial polyps usually present with abnormal uterine bleeding [36]. However, a large majority of polyps are asymptomatic and are incidentally discovered $[2,9]$. The diagnostic modalities that are commonly utilized to diagnose endometrial polyps include 2-dimensional transvaginal sonography (2D TVUS), 3-dimensional transvaginal sonography (3D TVUS), saline infusion sonography (SIS), hysterosalpingography (HSG), and hysteroscopy [37].

4.1. 2-Dimensional Transvaginal Sonography. An endometrial polyp usually appears as a hyperechoic endometrial mass with regular contours occupying the uterine cavity either partially or fully [15]. Occasionally, cystic spaces may appear within the polyp [38]. Performing sonography in the proliferative phase of the menstrual cycle often provides the most reliable results [39]. 2D TVUS, in experienced hands, can detect endometrial polyps accurately [40]. In a large study of 793 women, the sensitivity, specificity, positive predictive value (PPV), and negative predictive value (NPV) of $2 \mathrm{D}$ TVUS in detecting endometrial polyps were found to be $86 \%$, $94 \%, 91 \%$, and $90 \%$, respectively [41]. The addition of colorflow Doppler can improve the diagnostic capability of $2 \mathrm{D}$ TVUS by allowing visualization of the single feeding vessel present in endometrial polyps [9]. Color-flow Doppler, in some studies, has shown to increase the sensitivity of $2 \mathrm{D}$ TVUS from $91 \%$ to $97 \%$ [42].

4.2. 3-Dimensional Transvaginal Sonography. Compared to 2D sonography, 3D TVUS with color-flow Doppler allows for the measurement of endometrial volume, as well as endometrial and subendometrial vascularization indices [43, 44]. Some studies have suggested that using a combination of endometrial echogenicity, thickness, and volume with 3D TVUS may be better than single measurements with $2 \mathrm{D}$ TVUS for detecting endometrial polyps [43]. In contrast, others have shown that noncontrast 3D TVUS does not necessarily increase detection of endometrial polyps compared to $2 \mathrm{D}$ TVUS [45].

4.3. Saline Infusion Sonography. The addition of intrauterine contrast (saline or gel) increases the diagnostic accuracy of 2D TVUS and 3D TVUS [9]. Additional advantages of SIS include assessment of other uterine cavity abnormalities such as leiomyomata or adhesions and assessment of Müllerian anomalies, if needed [37, 46, 47]. Disadvantages of SIS are related to its learning curve [48] and patient discomfort caused by fluid instillation or leakage [49], as well as the theoretical risk of infection [50]. In a recent systematic review and meta-analysis of 20 studies comparing the diagnostic accuracy of SIS to hysteroscopy, the pooled sensitivity and specificity of SIS in the detection of all intrauterine abnormalities were $88 \%$ (95\% confidence interval [CI]: 85\%-90\%) and 94\% (95\% CI 93\%-96\%), respectively [37]. Overall, most studies reveal no significant difference between SIS and diagnostic hysteroscopy in diagnosing endometrial polyps [37]. Comparisons between 2D SIS and 3D SIS have also been made [51,52]. In one such study [51], the sensitivity, specificity, PPV, and NPV for 2D SIS in detecting intrauterine lesions were found to be $71.2 \%, 94.1 \%, 90.2 \%$, and $81.0 \%$, respectively. The overall accuracy was $84.2 \%$. For 3D SIS, the sensitivity was $94.2 \%$, specificity $98.5 \%$, positive predictive value $98.0 \%$, negative predictive value $95.7 \%$, and overall accuracy $96.7 \%$. The investigators concluded that 3D SIS was superior to 2D SIS and was comparable to hysteroscopy in diagnosing intrauterine lesions.

4.4. Hysterosalpingography. HSG allows imaging of the cervical canal, uterine cavity, and fallopian tubes with injection of contrast media using fluoroscopic visualization [53]. In general, the cervical canal or endometrial cavity is accessed using aseptic technique [53]. A small volume $(10-30 \mathrm{~mL})$ of contrast agent is administered under intermittent fluoroscopy to visualize the structures to be imaged [53]. Occasionally, 
postdrainage images can be obtained when endometrial pathology is suspected [53]. HSG has high sensitivity (98\%) but low specificity (34.6\%) and PPV (28.6\%) compared with hysteroscopy for endometrial polyps [54, 55].

4.5. Hysteroscopy. Hysteroscopy with guided biopsy is considered the gold standard for diagnosing endometrial polyps $[9,56]$. Hysteroscopy also facilitates assessment of size, number, and vascular characteristics of endometrial polyps [9]. Prior to the routine use of hysteroscopy, blind dilation and curettage were used for the diagnosis of endometrial polyps [57]. This technique, however, caused polyp fragmentation making histopathologic diagnosis difficult [58]. The low sensitivity of $8 \%$ to $46 \%$ and NPV of $7 \%$ to $58 \%$ of blind endometrial sampling compared to hysteroscopy with guided biopsy [59] suggests that the former technique should not be used for diagnosing endometrial polyps.

\section{Treatment Options}

5.1. Expectant Management. The natural course of endometrial polyps is not well understood [13,60]. Given that most polyps are benign, expectant management is a reasonable option in asymptomatic premenopausal women [9]. Small endometrial polyps $(<10 \mathrm{~mm})$ are thought to regress spontaneously in about $25 \%$ of cases $[61,62]$.

5.2. Medical Management. There is limited role of medical management for endometrial polyps [9, 62]. Levonorgestrel containing intrauterine devices have been used to reduce the incidence of tamoxifen-related endometrial polyps in some research settings [63]. Gonadotropin releasing hormone agonists have also been used as an adjunctive treatment before hysteroscopic resection [64]. However, there is little-to-no data supporting its utility as a first-line agent for treating endometrial polyps $[62,64]$.

5.3. Surgical Management. While endometrial polyps may resolve spontaneously and could possibly be amenable to hormonal therapy, definitive treatment options are largely surgical. Blind dilation and curettage can remove endometrial polyps in up to $8 \%$ of patients [9]. Addition of polyp forceps increases complete extraction of polyps in approximately $41 \%$ of patients [9]. In general, blind dilation and curettage can miss endometrial pathology in approximately $50 \%$ of cases and should therefore be avoided when hysteroscopy is available [57-59].

Hysteroscopic polypectomy remains the gold standard for both the diagnosis and treatment of endometrial polyps [9]. The choice of performing hysteroscopy in the office or outpatient surgical setting is generally dependent on patient preference, physician skill, and instrument availability $[9,65]$. While equivalent success rates have been reported in both settings, some data indicate that failure to remove a polyp is more likely in the office setting [65]. In contrast, other data suggest that office-based hysteroscopic polypectomy is safe and feasible in patients with endometrial or isthmic polyps
$<$ or $=20 \mathrm{~mm}$, independent of menopausal status or previous vaginal delivery [66].

Several hysteroscopic systems to resect endometrial polyps are currently available, monopolar loop cautery [9], bipolar systems [67], microscissors or graspers [9], and hysteroscopic morcellators $[68,69]$. Of these, the monopolar loop is more commonly available and of lower cost [9]. Comparative studies about the aforementioned methods with regard to costs and efficacy have recently begun to emerge. For example, in a prospective, randomized study of 100 patients comparing monopolar to bipolar electrode excision of endometrial polyps, the former technique was found to be better for nonfundal polyps or those $>20 \mathrm{~mm}$ compared to the latter technique, which was better for small, fundal polyps [70]. In another randomized study of 121 patients, removal of polyps using a hysteroscopic morcellator was found to be significantly quicker, less painful, more acceptable to women, and more likely to completely remove endometrial polyps compared to electrosurgical resection [71]. It is important to note that none of these studies were performed in infertile patients. The overall method of hysteroscopy polypectomy is generally the one which the clinician is trained with and most familiar with [9]. The risk of intrauterine adhesions after hysteroscopy polypectomy is low as the myometrium is generally not incised [72]. Other procedural risks associated with hysteroscopy polypectomy include infection, surgical bleeding, uterine perforation, fluid overload, or anesthesiarelated complications.

\section{Impact on Fertility}

The putative mechanisms by which endometrial polyps adversely impact fertility may be related to mechanical interference with sperm transportation or as space occupying lesions interfering with embryo implantation [5]. The glands and stroma in endometrial polyps are unresponsive to progesterone stimulation, leading to defective implantation at the site of the polyp [8]. Endometrial polyps may also induce local inflammatory changes, which can interfere with normal implantation and embryonic development [6, 73]. These inflammatory changes are mediated by increased number of mast cells in the endometrial cavity [74], as well as increased levels of matrix metalloproteinase- 2 and metalloproteinase- 9 [75]. Endometrial polyps can produce glycodelin, a glycoprotein that has been shown to inhibit natural killer cell activity, rendering the endometrium less receptive to implantation $[2,76]$. It is also speculated that endometrial polyps decrease messenger RNA levels of HOXA10 and HOXA11, which are known molecular markers of endometrial receptivity [7].

6.1. Natural Conception. Previous observational studies have shown that resection of endometrial polyps can improve natural conception rates, particularly in patients with unexplained infertility $[3,5]$. In one retrospective study of 78 patients, a pregnancy rate of $78.3 \%$ was noted after polypectomy compared to a pregnancy rate $42.1 \%$ in patients with normal uterine cavities [77]. Similarly, natural conception rates of 76\% [73] and 50\% [78] were reported after resection 
of endometrial polyps. In subfertile women, hysteroscopic polypectomy can improve fertility, with pregnancy rates ranging from $43 \%$ to $80 \%[73,79]$.

6.2. Intrauterine Insemination. Studies have shown that pregnancy rates are improved in patients undergoing polypectomy before undergoing intrauterine insemination (IUI) [2]. In one prospective randomized study involving 215 patients, patients who underwent polypectomy prior to IUI had an increased pregnancy rate (51.4\%) compared to patients who did not (25.4\%) [15]. These findings were similar to another independent study, which reported pregnancy rates of $40.7 \%$ and $22.3 \%$ in patients who did and did not undergo polypectomy before IUI, respectively [80]. Hysteroscopic resection of endometrial polyps $(\sim 16 \mathrm{~mm})$ prior to IUI for unexplained male or female factor has also been shown to increase the odds of clinical pregnancy (odds ratio 4.4, 95\% CI 2.5-8.0) for at least 2 years, compared to diagnostic hysteroscopy and polyp biopsy alone [81].

6.3. In Vitro Fertilization. Current evidence supports the resection of endometrial polyps diagnosed prior to commencement of IVF cycles [6]. The time interval between hysteroscopic resection of polyps and the subsequent IVF cycle does not seem to impact the success rates of the IVF cycle [82]. However, the management of newly diagnosed endometrial polyps during ovarian stimulation still remains controversial $[2,5]$. Some studies have shown that resection of newly diagnosed endometrial polyps during $\mathrm{COH}$ can decrease rates of pregnancy loss [18] and increase clinical pregnancy $[83,84]$ and live birth rates [77], while others have shown no such benefits $[85,86]$. In one of the earliest studies, 83 patients with polyps $<20 \mathrm{~mm}$ diagnosed during ovarian stimulation were divided into two groups [18]. The first group (49 patients) underwent IVF with fresh embryo transfer (ET), while the second group (34 patients) underwent hysteroscopic polypectomy immediately after oocyte retrieval. The cryopreserved embryos were thawed and transferred in a subsequent cycle. No difference in pregnancy rates was noted between the two groups. At least 2 other studies have confirmed the aforementioned findings $[85,86]$. These findings suggest that endometrial polyps $<20 \mathrm{~mm}$ during fresh IVF-ET cycles can be managed expectantly without compromising clinical pregnancy or live birth rates [2]. This was further confirmed by a retrospective study that showed no difference in the implantation, clinical pregnancy, or live birth rates after fresh IVF-ET cycles when patients with newly diagnosed endometrial polyps were compared to those with normal endometrial stripes [87]. Most recently, our group [2] reported that newly diagnosed endometrial polyps $(<20 \mathrm{~mm})$ during ovarian stimulation are associated with an increased biochemical pregnancy rate, without adversely impacting clinical pregnancy or live birth rates after fresh IVF cycles. Thus, one may hypothesize that small endometrial polyps can create a hostile environment for early embryo development; however, if the embryo does overcome this initial insult, the risk of future miscarriage is primarily related to embryonic aneuploidy or other endometrial factors [2].

\section{Conclusions}

Endometrial polyps are commonly seen in infertile women [6]. The overall evidence suggests a detrimental effect of polyps on fertility [6]. Conservative management of small and asymptomatic polyps is reasonable in most cases [9]. However, surgical resection of endometrial polyps is recommended in infertile patients to possibly increase natural conception and assisted reproductive pregnancy rates [9]. Hysteroscopic polypectomy remains the gold standard for surgical treatment, though evidence regarding the cost and efficacy of different methods for hysteroscopic resection of polyps in the inpatient and outpatient settings has begun to emerge. Management of newly diagnosed endometrial polyps during IVF should be individualized according to the patient's reproductive history, polyp size and location, ovarian stimulation response, the number of good quality embryos, and the individual clinic's success rate with cryopreserved embryo transfer $[2,6]$.

\section{Conflict of Interests}

The authors declare that there is no conflict of interests regarding the publication of this paper.

\section{References}

[1] E. R. Norwitz, D. J. Schust, and S. J. Fisher, "Implantation and the survival of early pregnancy," The New England Journal of Medicine, vol. 345, no. 19, pp. 1400-1408, 2001.

[2] R. T. Elias, N. Pereira, F. S. Karipcin, Z. Rosenwaks, and S. D. Spandorfer, "Impact of newly diagnosed endometrial polyps during controlled ovarian hyperstimulation on in vitro fertilization outcomes," Journal of Minimally Invasive Gynecology, vol. 22, no. 4, pp. 590-594, 2015.

[3] J. Bosteels, J. Kasius, S. Weyers, F. J. Broekmans, B. W. J. Mol, and T. M. D'Hooghe, "Hysteroscopy for treating subfertility associated with suspected major uterine cavity abnormalities," Cochrane Database of Systematic Reviews, no. 2, Article ID CD009461, 2015.

[4] M. M. Carneiro, "What is the role of hysteroscopic surgery in the management of female infertility? A review of the literature," Surgery Research and Practice, vol. 2014, Article ID 105412, 6 pages, 2014.

[5] E. Taylor and V. Gomel, "The uterus and fertility," Fertility and Sterility, vol. 89, no. 1, pp. 1-16, 2008.

[6] K. Afifi, S. Anand, S. Nallapeta, and T. A. Gelbaya, "Management of endometrial polyps in subfertile women: a systematic review," European Journal of Obstetrics \& Gynecology and Reproductive Biology, vol. 151, no. 2, pp. 117-121, 2010.

[7] B. W. Rackow, E. Jorgensen, and H. S. Taylor, "Endometrial polyps affect uterine receptivity," Fertility and Sterility, vol. 95, no. 8, pp. 2690-2692, 2011.

[8] K. Mittal, L. Schwartz, S. Goswami, and R. Demopoulos, "Estrogen and progesterone receptor expression in endometrial polyps," International Journal of Gynecological Pathology, vol. 15, no. 4, pp. 345-348, 1996.

[9] American Association of Gynecologic Laparoscopists, "AAGL practice report: practice guidelines for the diagnosis and management of endometrial polyps," Journal of Minimally Invasive Gynecology, vol. 19, no. 1, pp. 3-10, 2012. 
[10] G. Silló-Seidl, "The analysis of the endometrium of 1,000 sterile women," Hormones, vol. 2, no. 2, pp. 70-75, 1971.

[11] M. Lieng, O. Istre, L. Sandvik, and E. Qvigstad, "Prevalence, 1year regression rate, and clinical significance of asymptomatic endometrial polyps: cross-sectional study," Journal of Minimally Invasive Gynecology, vol. 16, no. 4, pp. 465-471, 2009.

[12] L.-J. Van Bogaert, "Clinicopathologic findings in endometrial polyps," Obstetrics and Gynecology, vol. 71, no. 5, pp. 771-773, 1988.

[13] R. Haimov-Kochman, R. Deri-Hasid, Y. Hamani, and E. Voss, "The natural course of endometrial polyps: could they vanish when left untreated?" Fertility and Sterility, vol. 92, no. 2, pp. 828.e11-828.e12, 2009.

[14] M. D. Hinckley and A. A. Milki, "1000 office-based hysteroscopies prior to in vitro fertilization: feasibility and findings," Journal of the Society of Laparoendoscopic Surgeons, vol. 8, no. 2, pp. 103-107, 2004.

[15] T. Pérez-Medina, J. Bajo-Arenas, F. Salazar et al., "Endometrial polyps and their implication in the pregnancy rates of patients undergoing intrauterine insemination: a prospective, randomized study," Human Reproduction, vol. 20, no. 6, pp. 1632-1635, 2005.

[16] E. Dreisler, S. Stampe Sorensen, P. H. Ibsen, and G. Lose, "Prevalence of endometrial polyps and abnormal uterine bleeding in a Danish population aged 20-74 years," Ultrasound in Obstetrics and Gynecology, vol. 33, no. 1, pp. 102-108, 2009.

[17] S. C. Lee, A. M. Kaunitz, L. Sanchez-Ramos, and R. M. Rhatigan, "The oncogenic potential of endometrial polyps: a systematic review and meta-analysis," Obstetrics \& Gynecology, vol. 116, no. 5, pp. 1197-1205, 2010.

[18] A. Lass, G. Williams, N. Abusheikha, and P. Brinsden, "The effect of endometrial polyps on outcomes of in vitro fertilization (IVF) cycles," Journal of Assisted Reproduction and Genetics, vol. 16, no. 8, pp. 410-415, 1999.

[19] R. Onalan, G. Onalan, E. Tonguc, T. Ozdener, M. Dogan, and L. Mollamahmutoglu, "Body mass index is an independent risk factor for the development of endometrial polyps in patients undergoing in vitro fertilization," Fertility and Sterility, vol. 91, no. 4, pp. 1056-1060, 2009.

[20] L. Nappi, U. Indraccolo, A. D. S. Sardo et al., "Are diabetes, hypertension, and obesity independent risk factors for endometrial polyps?" Journal of Minimally Invasive Gynecology, vol. 16, no. 2, pp. 157-162, 2009.

[21] L.-C. F. Vilodre, R. Bertat, R. Petters, and F. M. Reis, "Cervical polyp as risk factor for hysteroscopically diagnosed endometrial polyps," Gynecologic and Obstetric Investigation, vol. 44, no. 3, pp. 191-195, 1997.

[22] J. H. McBean, M. Gibson, and J. R. Brumsted, "The association of intrauterine filling defects on hysterosalpingogram with endometriosis," Fertility and Sterility, vol. 66, no. 4, pp. 522-526, 1996.

[23] C. Exacoustos, E. Zupi, B. Cangi, M. Chiaretti, D. Arduini, and C. Romanini, "Endometrial evaluation in postmenopausal breast cancer patients receiving tamoxifen: an ultrasound, color flow Doppler, hysteroscopic and histological study," Ultrasound in Obstetrics \& Gynecology, vol. 6, no. 6, pp. 435-442, 1995.

[24] C. Saccardi, S. Gizzo, K. Ludwig et al., "Endometrial polyps in women affected by levothyroxine-treated hypothyroidismhistological features, immunohistochemical findings, and possible explanation of etiopathogenic mechanism: a pilot study," BioMed Research International, vol. 2013, Article ID 503419, 5 pages, 2013.
[25] L. Pal, A. L. Niklaus, M. Kim, S. Pollack, and N. Santoro, "Heterogeneity in endometrial expression of aromatase in polyp-bearing uteri," Human Reproduction, vol. 23, no. 1, pp. 80-84, 2008.

[26] H. Maia Jr., K. Pimentel, T. M. Correia Silva et al., "Aromatase and cyclooxygenase-2 expression in endometrial polyps during the menstrual cycle," Gynecological Endocrinology, vol. 22, no. 4, pp. 219-224, 2006.

[27] A. Pinheiro, A. Antunes Jr., L. Andrade, L. De Brot, A. M. PintoNeto, and L. Costa-Paiva, "Expression of hormone receptors, Bcl-2, Cox-2 and Ki67 in benign endometrial polyps and their association with obesity," Molecular Medicine Reports, vol. 9, no. 6, pp. 2335-2341, 2014.

[28] P. dal Cin, S. Wanschura, B. Kazmierczak et al., "Amplification and expression of the HMGIC gene in a benign endometrial polyp," Genes Chromosomes and Cancer, vol. 22, no. 2, pp. 9599, 1998.

[29] P. dal Cin, R. Vanni, S. Marras et al., "Four cytogenetic subgroups can be identified in endometrial polyps," Cancer Research, vol. 55, no. 7, pp. 1565-1568, 1995.

[30] A. Ben-Arie, C. Goldchmit, Y. Laviv et al., "The malignant potential of endometrial polyps," European Journal of Obstetrics Gynecology and Reproductive Biology, vol. 115, no. 2, pp. 206210, 2004.

[31] A. Shushan, A. Revel, and N. Rojansky, "How often are endometrial polyps malignant?" Gynecologic and Obstetric Investigation, vol. 58, no. 4, pp. 212-215, 2004.

[32] S. H. Bakour, K. S. Khan, and J. K. Gupta, "The risk of premalignant and malignant pathology in endometrial polyps," Acta Obstetricia et Gynecologica Scandinavica, vol. 79, no. 4, pp. 317-320, 2000.

[33] E. Ferrazzi, E. Zupi, F. P. Leone et al., "How often are endometrial polyps malignant in asymptomatic postmenopausal women? A multicenter study," American Journal of Obstetrics and Gynecology, vol. 200, no. 3, pp. 235.e1-235.e6, 2009.

[34] A. Papadia, D. Gerbaldo, E. Fulcheri et al., "The risk of premalignant and malignant pathology in endometrial polyps: should every polyp be resected?" Minerva Ginecologica, vol. 59, no. 2, pp. 117-124, 2007.

[35] L. Bernstein, D. Deapen, J. R. Cerhan et al., "Tamoxifen therapy for breast cancer and endometrial cancer risk," Journal of the National Cancer Institute, vol. 91, no. 19, pp. 1654-1662, 1999.

[36] M. G. Munro, H. O. D. Critchley, M. S. Broder, and I. S. Fraser, "FIGO classification system (PALM-COEIN) for causes of abnormal uterine bleeding in nongravid women of reproductive age," International Journal of Gynecology and Obstetrics, vol. 113, no. 1, pp. 3-13, 2011.

[37] S. Seshadri, T. El-Toukhy, A. Douiri, K. Jayaprakasan, and Y. Khalaf, "Diagnostic accuracy of saline infusion sonography in the evaluation of uterine cavity abnormalities prior to assisted reproductive techniques: a systematic review and metaanalyses," Human Reproduction Update, vol. 21, no. 2, pp. 262274, 2015

[38] C. A. Hulka, D. A. Hall, K. McCarthy, and J. F. Simeone, "Endometrial polyps, hyperplasia, and carcinoma in postmenopausal women: differentiation with endovaginal sonography," Radiology, vol. 191, no. 3, pp. 755-758, 1994.

[39] K. M. Nalaboff, J. S. Pellerito, and E. Ben-Levi, "Imaging the endometrium: disease and normal variants," Radiographics, vol. 21, no. 6, pp. 1409-1424, 2001. 
[40] J. Shalev, I. Meizner, I. Bar-Hava, D. Dicker, R. Mashiach, and Z. Ben-Rafael, "Predictive value of transvaginal sonography performed before routine diagnostic hysteroscopy for evaluation of infertility," Fertility and Sterility, vol. 73, no. 2, pp. 412-417, 2000.

[41] P. Vercellini, I. Cortesi, S. Oldani, M. Moschetta, O. De Giorgi, and P. G. Crosignani, "The role of transvaginal ultrasonography and outpatient diagnostic hysteroscopy in the evaluation of patients with menorrhagia," Human Reproduction, vol. 12, no. 8, pp. 1768-1771, 1997.

[42] A. Jakab, L. Óvári, B. Juhász, L. Birinyi, G. Bacskó, and Z. Tóth, "Detection of feeding artery improves the ultrasound diagnosis of endometrial polyps in asymptomatic patients," European Journal of Obstetrics Gynecology and Reproductive Biology, vol. 119, no. 1, pp. 103-107, 2005.

[43] L. Fang, Y. Su, Y. Guo, and Y. Sun, "Value of 3-dimensional and power Doppler sonography for diagnosis of endometrial polyps," Journal of Ultrasound in Medicine, vol. 32, no. 2, pp. 247-255, 2013.

[44] F. Ahmadi, F. Zafarani, H. Haghighi, M. Niknejadi, and A. V. T. Dizaj, "Application of 3D ultrasonography in detection of uterine abnormalities," International Journal of Fertility and Sterility, vol. 4, no. 4, pp. 144-147, 2011.

[45] R. La Torre, C. De Felice, C. De Angelis, F. Coacci, M. Mastrone, and E. V. Cosmi, "Transvaginal sonographic evaluation of endometrial polyps: a comparison with two dimensional and three dimensional contrast sonography," Clinical and Experimental Obstetrics and Gynecology, vol. 26, no. 3-4, pp. 171-173, 1999.

[46] N. Makris, N. Skartados, K. Kalmantis, G. Mantzaris, A. Papadimitriou, and A. Antsaklis, "Evaluation of abnormal uterine bleeding by transvaginal 3-D hysterosonography and diagnostic hysteroscopy," European Journal of Gynaecological Oncology, vol. 28, no. 1, pp. 39-42, 2007.

[47] F. W. Jansen, C. D. de Kroon, H. van Dongen, C. Grooters, L. Louwé, and T. Trimbos-Kemper, "Diagnostic hysteroscopy and saline infusion sonography: prediction of intrauterine polyps and myomas," The Journal of Minimally Invasive Gynecology, vol. 13, no. 4, pp. 320-324, 2006.

[48] N. Exalto, C. Stappers, L. A. M. van Raamsdonk, and M. H. Emanuel, "Gel instillation sonohysterography: first experience with a new technique," Fertility and Sterility, vol. 87, no. 1, pp. 152-155, 2007.

[49] C. H. Syrop and V. Sahakian, "Transvaginal sonographic detection of endometrial polyps with fluid contrast augmentation," Obstetrics and Gynecology, vol. 79, no. 6, pp. 1041-1043, 1992.

[50] V. I. Shavell, I. P. Le, and F. D. Yelian, "Tuboovarian abscess after saline infusion sonohysterography: an unusual complication," Journal of Minimally Invasive Gynecology, vol. 16, no. 5, pp. 652654, 2009.

[51] W. El-Sherbiny, A. El-Mazny, N. Abou-Salem, and W. S. Mostafa, "The diagnostic accuracy of two- vs three-dimensional sonohysterography for evaluation of the uterine cavity in the reproductive age," Journal of Minimally Invasive Gynecology, vol. 22, no. 1, pp. 127-131, 2015.

[52] N. Abou-Salem, A. Elmazny, and W. El-Sherbiny, "Value of 3dimensional sonohysterography for detection of intrauterine lesions in women with abnormal uterine bleeding," The Journal of Minimally Invasive Gynecology, vol. 17, no. 2, pp. 200-204, 2010.

[53] ACR Practice Parameter for the Performance of Hysterosalpingography Res. 50-2011, Amended 2014 (Res. 39), 2015,
http://www.acr.org/Quality-Safety/Standards-Guidelines/ Practice-Guidelines-by-Modality/Radiography.

[54] S. Preutthipan and V. Linasmita, "A prospective comparative study between hysterosalpingography and hysteroscopy in the detection of intrauterine pathology in patients with infertility," Journal of Obstetrics and Gynaecology Research, vol. 29, no. 1, pp. 33-37, 2003.

[55] S. R. Soares, M. M. B. B. Dos Reis, and A. F. Camargos, "Diagnostic accuracy of sonohysterography, transvaginal sonography, and hysterosalpingography in patients with uterine cavity diseases," Fertility and Sterility, vol. 73, no. 2, pp. 406-411, 2000.

[56] K. W. K. Lo and P. M. Yuen, "The role of outpatient diagnostic hysteroscopy in identifying anatomic pathology and histopathology in the endometrial cavity," Journal of the American Association of Gynecologic Laparoscopists, vol. 7, no. 3, pp. 381-385, 2000

[57] R. J. Gimpelson and H. O. Rappold, "A comparative study between panoramic hysteroscopy with directed biopsies and dilatation and curettage. A review of 276 cases," American Journal of Obstetrics and Gynecology, vol. 158, no. 3, pp. 489492, 1988.

[58] R. Svirsky, N. Smorgick, U. Rozowski et al., "Can we rely on blind endometrial biopsy for detection of focal intrauterine pathology?" The American Journal of Obstetrics and Gynecology, vol. 199, no. 2, pp. 115.el-115.e3, 2008.

[59] S. Bettocchi, O. Ceci, M. Vicino, F. Marello, L. Impedovo, and L. Selvaggi, "Diagnostic inadequacy of dilatation and curettage," Fertility and Sterility, vol. 75, no. 4, pp. 803-805, 2001.

[60] D. J. DeWaay, C. H. Syrop, I. E. Nygaard, W. A. Davis, and B. J. Van Voorhis, "Natural history of uterine polyps and leiomyomata," Obstetrics and Gynecology, vol. 100, no. 1, pp. 3-7, 2002.

[61] Y. Hamani, I. Eldar, H. Y. Sela, E. Voss, and R. HaimovKochman, "The clinical significance of small endometrial polyps," European Journal of Obstetrics Gynecology and Reproductive Biology, vol. 170, no. 2, pp. 497-500, 2013.

[62] M. Lieng, O. Istre, and E. Qvigstad, “Treatment of endometrial polyps: a systematic review," Acta Obstetricia et Gynecologica Scandinavica, vol. 89, no. 8, pp. 992-1002, 2010.

[63] F. J. E. Gardner, J. C. Konje, S. C. Bell et al., "Prevention of tamoxifen induced endometrial polyps using a levonorgestrel releasing intrauterine system. Long-term follow-up of a randomised control trial," Gynecologic Oncology, vol. 114, no. 3, pp. 452-456, 2009.

[64] P. Vercellini, L. Trespidi, T. Bramante, S. Panazza, F. Mauro, and P. G. Crosignani, "Gonadotropin releasing hormone agonist treatment before hysteroscopic endometrial resection," International Journal of Gynecology \& Obstetrics, vol. 45, no. 3, pp. 235239, 1994.

[65] N. A. Cooper, T. J. Clark, L. Middleton et al., "Outpatient versus inpatient uterine polyp treatment for abnormal uterine bleeding: randomised controlled non-inferiority study," British Medical Journal, vol. 350, article h1398, 2015.

[66] P. Litta, E. Cosmi, C. Saccardi, C. Esposito, R. Rui, and G. Ambrosini, "Outpatient operative polypectomy using a $5 \mathrm{~mm}$ hysteroscope without anaesthesia and/or analgesia: advantages and limits," European Journal of Obstetrics Gynecology and Reproductive Biology, vol. 139, no. 2, pp. 210-214, 2008.

[67] A. Golan, R. Sagiv, M. Berar, S. Ginath, and M. Glezerman, "Bipolar electrical energy in physiologic solution-a revolution in operative hysteroscopy," Journal of the American Association of Gynecologic Laparoscopists, vol. 8, no. 2, pp. 252-258, 2001. 
[68] M. H. Emanuel and K. Wamsteker, "The Intra Uterine Morcellator: a new hysteroscopic operating technique to remove intrauterine polyps and myomas," The Journal of Minimally Invasive Gynecology, vol. 12, no. 1, pp. 62-66, 2005.

[69] H. van Dongen, M. H. Emanuel, R. Wolterbeek, J. B. Trimbos, and F. W. Jansen, "Hysteroscopic morcellator for removal of intrauterine polyps and myomas: a randomized controlled pilot study among residents in training," The Journal of Minimally Invasive Gynecology, vol. 15, no. 4, pp. 466-471, 2008.

[70] L. Muzii, F. Bellati, M. Pernice, N. Manci, R. Angioli, and P. B. Panici, "Resectoscopic versus bipolar electrode excision of endometrial polyps: a randomized study," Fertility and Sterility, vol. 87, no. 4, pp. 909-917, 2007.

[71] P. P. Smith, L. J. Middleton, M. Connor, and T. J. Clark, "Hysteroscopic morcellation compared with electrical resection of endometrial polyps: a randomized controlled trial," Obstetrics and Gynecology, vol. 123, no. 4, pp. 745-751, 2014.

[72] R. Deans and J. Abbott, "Review of intrauterine adhesions," Journal of Minimally Invasive Gynecology, vol. 17, no. 5, pp. 555569, 2010.

[73] B. Śpiewankiewicz, J. Stelmachów, W. Sawicki, K. Cendrowski, P. Wypych, and K. Świderska, "The effectiveness of hysteroscopic polypectomy in cases of female infertility," Clinical and Experimental Obstetrics \& Gynecology, vol. 30, no. 1, pp. 23-25, 2003.

[74] M. Al-Jefout, K. Black, L. Schulke et al., "Novel finding of high density of activated mast cells in endometrial polyps," Fertility and Sterility, vol. 92, no. 3, pp. 1104-1106, 2009.

[75] N. Inagaki, L. Ung, T. Otani, D. Wilkinson, and A. Lopata, "Uterine cavity matrix metalloproteinases and cytokines in patients with leiomyoma, adenomyosis or endometrial polyp," European Journal of Obstetrics Gynecology and Reproductive Biology, vol. 111, no. 2, pp. 197-203, 2003.

[76] S. S. Richlin, S. Ramachandran, A. Shanti, A. A. Murphy, and S. Parthasarathy, "Glycodelin levels in uterine flushings and in plasma of patients with leiomyomas and polyps: implications for implantation," Human Reproduction, vol. 17, no. 10, pp. 27422747, 2002.

[77] N. N. Varasteh, R. S. Neuwirth, B. Levin, and M. D. Keltz, "Pregnancy rates after hysteroscopic polypectomy and myomectomy in infertile women," Obstetrics and Gynecology, vol. 94, no. 2, pp. 168-171, 1999.

[78] T. A. Shokeir, H. M. Shalan, and M. M. El-Shafei, "Significance of endometrial polyps detected hysteroscopically in eumenorrheic infertile women," Journal of Obstetrics and Gynaecology Research, vol. 30, no. 2, pp. 84-89, 2004.

[79] R. F. Valle, “Therapeutic hysteroscopy in infertility," International Journal of Fertility, vol. 29, no. 3, pp. 143-148, 1984.

[80] T. Kalampokas, D. Tzanakaki, S. Konidaris, C. Iavazzo, E. Kalampokas, and O. Gregoriou, "Endometrial polyps and their relationship in the pregnancy rates of patients undergoing intrauterine insemination," Clinical and Experimental Obstetrics and Gynecology, vol. 39, no. 3, pp. 299-302, 2012.

[81] J. Bosteels, J. Kasius, S. Weyers, F. J. Broekmans, B. W. J. Mol, and T. M. D’Hooghe, “Treating suspected uterine cavity abnormalities by hysteroscopy to improve reproductive outcome in women with unexplained infertility or prior to IUI, IVF, or ICSI," Gynecological Surgery, vol. 10, no. 3, pp. 165-167, 2013.

[82] O. G. Eryilmaz, C. Gulerman, E. Sarikaya, H. Yesilyurt, F. Karsli, and N. Cicek, "Appropriate interval between endometrial polyp resection and the proceeding IVF start," Archives of Gynecology and Obstetrics, vol. 285, no. 6, pp. 1753-1757, 2012.
[83] I. Stamatellos, A. Apostolides, P. Stamatopoulos, and J. Bontis, "Pregnancy rates after hysteroscopic polypectomy depending on the size or number of the polyps," Archives of Gynecology and Obstetrics, vol. 277, no. 5, pp. 395-399, 2008.

[84] A. Yanaihara, T. Yorimitsu, H. Motoyama, S. Iwasaki, and T. Kawamura, "Location of endometrial polyp and pregnancy rate in infertility patients," Fertility and Sterility, vol. 90, no. 1, pp. 180-182, 2008.

[85] M. Isikoglu, Z. Berkkanoglu, Z. Senturk, K. Coetzee, and K. Ozgur, "Endomerial polyps smaller than $1.5 \mathrm{~cm}$ do not affect ICSI outcome," Reproductive BioMedicine Online, vol. 12, no. 2, pp. 199-204, 2006.

[86] B. Tiras, U. Korucuoglu, M. Polat, H. B. Zeyneloglu, A. Saltik, and H. Yarali, "Management of endometrial polyps diagnosed before or during ICSI cycles," Reproductive BioMedicine Online, vol. 24, no. 1, pp. 123-128, 2012.

[87] J. H. Check, C. A. Bostick-Smith, J. K. Choe, J. Amui, and D. Brasile, "Matched controlled study to evaluate the effect of endometrial polyps on pregnancy and implantation rates following in vitro fertilization-embryo transfer (IVF-ET)," Clinical and Experimental Obstetrics and Gynecology, vol. 38, no. 3, pp. 206-208, 2011. 


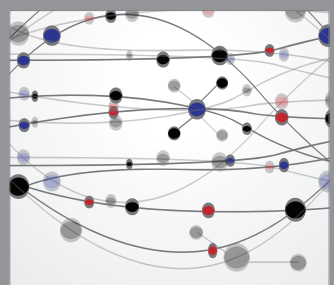

The Scientific World Journal
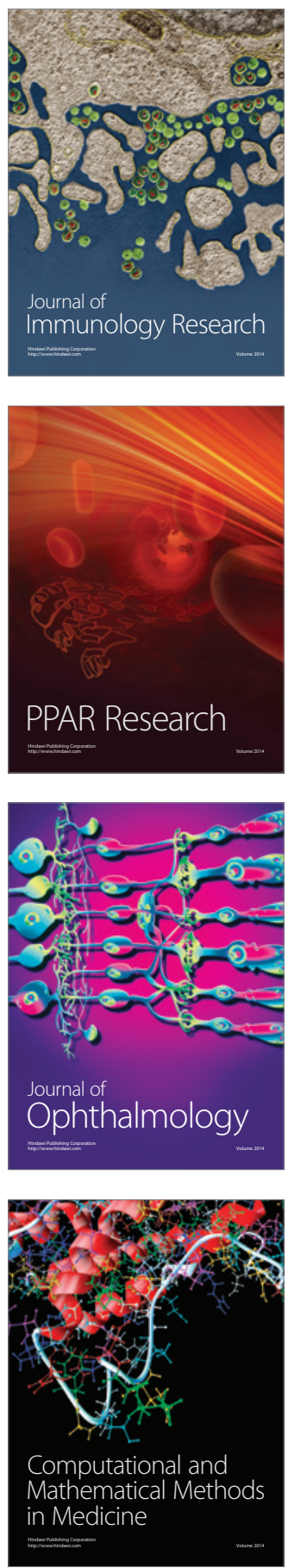

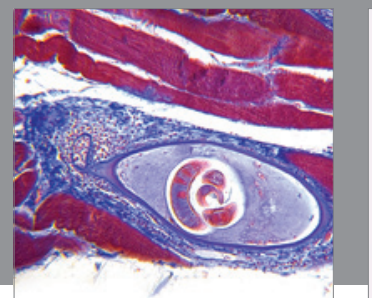

Gastroenterology

Research and Practice
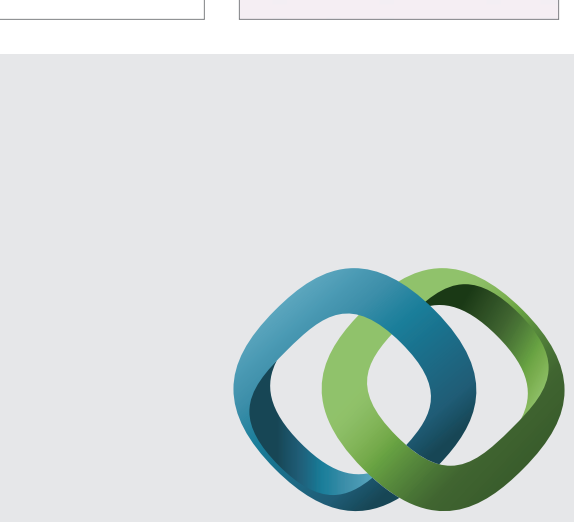

\section{Hindawi}

Submit your manuscripts at

http://www.hindawi.com
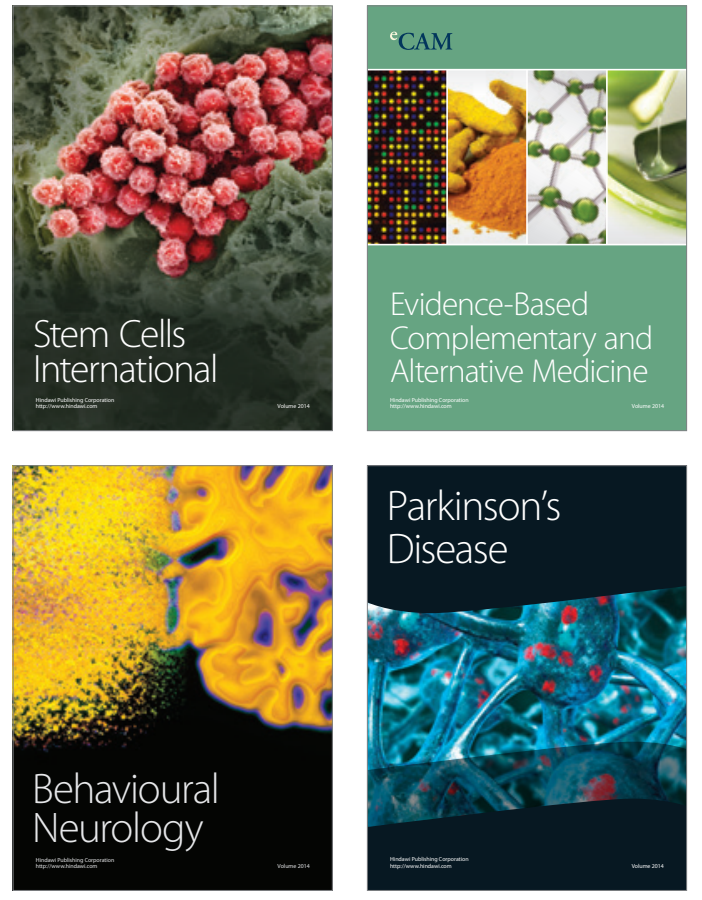
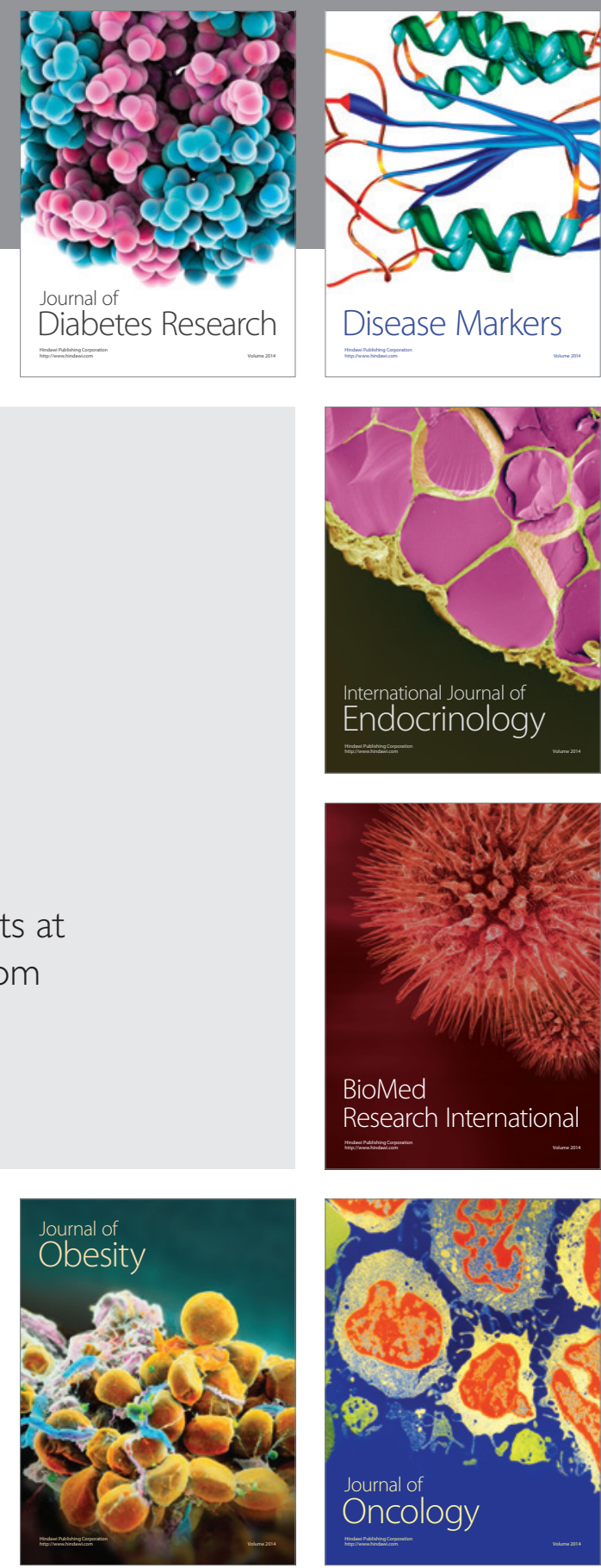

Disease Markers
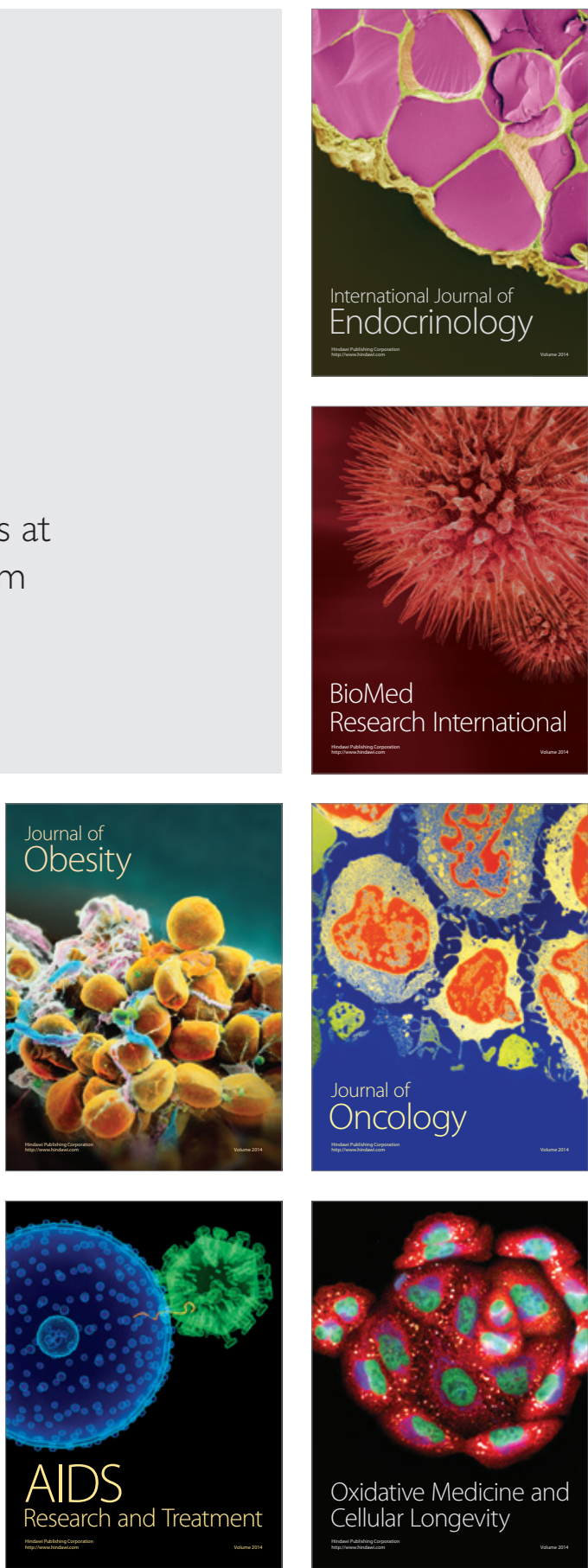